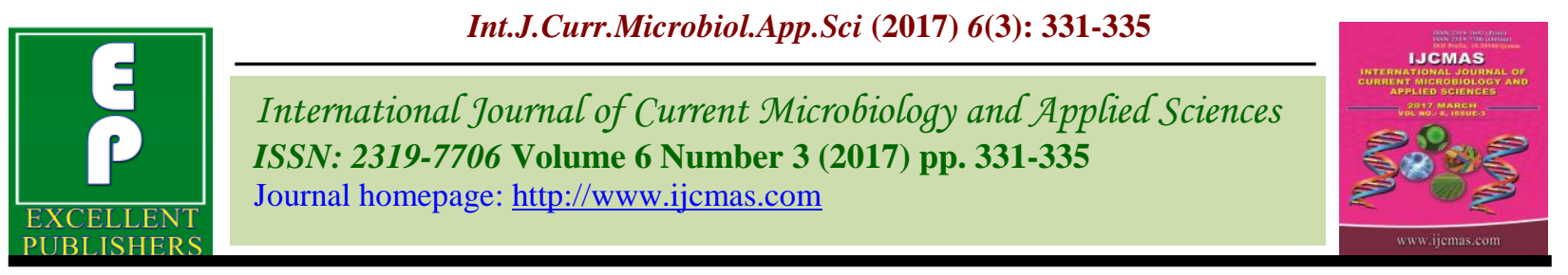

Original Research Article https://doi.org/10.20546/ijcmas.2017.603.037

\title{
Food Borne Outbreak of Gastroenteritis Due to Shigella sonnei in North - West Region of Rajasthan, India
}

\author{
Reena Goyal*, Taruna Swami, Deep Shikhar Acharya and Divya Sharma \\ Department of Microbiology, S. P. Medical College, Bikaner, Rajasthan, India \\ *Corresponding author
}

\begin{tabular}{|c|c|}
\hline & A B S T R A C T \\
\hline $\begin{array}{l}\text { K e y w o r d s } \\
\text { Shigella sonnei, } \\
\text { Gastroenteritis, } \\
\text { Food borne diseases. }\end{array}$ & \multirow{3}{*}{$\begin{array}{l}\text { Shigella is an important food borne pathogen in India. Shigella sonnei and } \\
\text { non-agglutinable Shigella seem to be steadily surfacing. We are reporting a } \\
\text { food borne outbreak of Shigella sonnei from our region. Shigella sonnei } \\
\text { were isolated in } 7 \text { samples of } 9 \text { patients who had consumed common food } \\
\text { made up of rice, potato, milk and water. The strains were sensitive to } \\
\text { ampicillin, chloramphenicol, ceftiaxone, tetracycline and furazolidone. } \\
\text { Patients were treated successfully with oral rehydration therapy, } \\
\text { metronidazole and ceftriaxone. }\end{array}$} \\
\hline Article Info & \\
\hline $\begin{array}{l}\text { Accepted: } \\
\text { 10 February } 2017 \\
\text { Available Online: } \\
\text { 10 March } 2017\end{array}$ & \\
\hline
\end{tabular}

\section{Introduction}

Food borne diseases cause morbidity and mortality in the general population and they have emerged as a growing public health and economic problem in many countries during the last 2 decades. Food borne disease can be defined as any disease of an infectious or toxic nature caused by or thought to be caused by the consumption of food or water (Adams et al., 2003). The global burden of food borne disease is currently unknown but the World Health Organization (WHO) has responded to this data gap by launching a new initiative to provide better estimates. In 2005 it was reported that 1.8 million people died from diarrheal diseases largely due to contaminated food and water (Newell et al., 2010). The scientific investigations/reports on outbreak of food borne diseases in India for the past 29 (1980-2009) years indicated that a total of
37 outbreaks involving 3,485 persons have been affected due to food poisoning (Sudershan et al., 2012).

Infection with Shigella spp. is a major cause of food borne diseases, which have increased considerably during the past decades, but only a small fraction of cases are reported (Scallan et al., 2011). Shigellosis, caused by members of the bacterial genus Shigella, is a severe and occasionally life threatening diarrheal infection. Worldwide, Shigella spp. are the most common cause of acute bloody diarrhoea (dysentery) and are responsible for a significant proportion of the burden of morbidity and mortality associated with diarrheal disease (Thapar et al., 2004; Kotloff et al., 2013). In Asia alone, it is estimated that there are 125 million infections and 14,000 
deaths due to shigellosis annually. $S$. dysenteriae and $S$. flexneri are the predominant species in the tropics; clinically, $S$. dysenteriae serotype 1 is associated with severe disease, large outbreaks, or epidemics. $S$. sonnei occurs more frequently in industrialized than in developing countries and causes milder illness than $S$. dysenteriae and S. flexneri. However, occasional food borne outbreaks by antimicrobial drugresistant $S$. sonnei have been reported from the United States, Japan, and European countries, mostly among children (2-5 yrs). During recent years, in Thailand, Vietnam, and Sri Lanka, the predominant species has shifted from $S$. flexneri to $S$. sonnei, a phenomenon possibly linked with country's level of development (Von et al., 2006). The epidemiology of Shigella infections in developing countries is changing. S. sonnei seems to be replacing the more antigenically diverse $S$. flexneri in regions undergoing economic development and improvements in water quality. As a result, $S$. sonnei outbreaks are also being reported from developing countries (Prehel et al., 2007).

\section{Materials and Methods}

The study included 9 patients admitted in Medicine ward of our tertiary care hospital in North - West region of Rajasthan. They attended a marriage concert at a village in June 2016. There was a history of consumption of local food made up of rice, potato, milk and water. Around 100 persons attended the party, approximately 40 persons within 12 -13 hours of consumption of food, were having complains of passing watery stool initially, which were later on blood and mucus tinged ( $>8$ times a day), high grade fever, abdominal pain, tenesmus, with or without nausea and vomiting. Some patients were admitted at Government Hospital locally. But few were having more severe symptoms and were referred to tertiary care hospital of our Institute. Age of patients varied from $5 \mathrm{yr}$ to $60 \mathrm{yr}$. Stool samples from these admitted patients in medicine ward were collected and immediately transferred to Department of Microbiology, for isolation of enteric pathogens. On gross examination stool samples were liquid in consistency, reddish in colour. On microscopy, there were pus cells, $\mathrm{RBC}$ and bacteria in large numbers and bacteria were non-motile. There were no parasitic ova and cyst seen. Immediately samples were inoculated over Blood Agar, McConkey agar, DCA agar, Tetrathionate broth, and incubated at $37^{\circ} \mathrm{C}$ for $24 \mathrm{hrs}$. After incubation, the colonies were observed and the identification of pure culture from stool samples was done by studying colony characteristics, microscopy, motility test, and biochemical tests such as catalase, oxidase and carbohydrate fermentation tests by conventional method. The isolates were serotyped using slide agglutination with specific antisera (Denka Seiken Co. Ltd. Tokyo, Japan). Antimicrobial susceptibility test was performed according to the standard guideline of the Clinical and Laboratory Standards Institute (Clinical and Laboratory Standards Institute, 2005). Antibiotics used were ampicillin, azithromycin, tetracycline, chloramphanicol, ceftriaxone, cefixime, nalidixic acid, sulfamoxazole / trimethoprim and furazolidone. All the isolates were sent to National Centre for Disease Control, Sham Nath Marg, Delhi and National Institute of Cholera and Enteric Diseases (Kolkata, India) for confirmation.

\section{Results and Discussion}

Of the 9 diarrhoea / dysentery stool samples screened, Shigella sonnei were isolated in 7 samples. E. coli was isolated from remaining two samples. Antibiotic sensitivity profile of Shigella sonnei were noted and were sensitive to ampicillin, chloramphenicol, ceftriaxone, cefixime, tetracycline and furazolidone. Few were intermediate sensitive to tetracycline. 
Resistance was seen towards azithromycin, ciprofloxacin, nalidixic acid, sulfamoxazole / trimethoprim. All the patients were treated successfully with oral rehydration therapy, ceftiaxone and metronidazole and discharged after complete recovery.

Infection with Shigella spp. is a major cause of food borne diseases, which have increased considerably during the past decades, but only a small fraction of cases are reported. $S$. dysenteriae and $S$. flexneri are the predominant species in the tropics; clinically, $S$. dysenteriae serotype 1 is associated with severe disease, large outbreaks, or epidemics. $S$. sonnei occurs more frequently in industrialized than in developing countries and causes milder illness than $S$. dysenteriae and S. flexneri. However, occasional food borne outbreaks by antimicrobial drugresistant $S$. sonnei have been reported from the United States, Japan, and European countries, mostly among children. During recent years, in Thailand, Vietnam, and Sri Lanka, the predominant species has shifted from $S$. flexneri to $S$. sonnei, a phenomenon possibly linked with country's level of development As a result, S. sonnei outbreaks are also being reported from developing countries.

In India, Outbreaks caused by S. sonnei have also been reported recently from various part like West Bengal (2007), Kerala (2009) and Maharashtra (2010) (Nandy et al., 2009). Food borne outbreaks of $S$. sonnei was reported in year 2009 from Kerala where local food made of rice, lentil, milk and water was implicated as the source. In Maharashtra in year 2010 about 150 persons suffered from Shigellosis after eating in a Madrasa (religious place) these reports support the extension of $S$. sonnei into India. Our study supports emergence of $S$. sonnei in North West Rajasthan in year 2016.
Shigellosis remains a public health concern throughout the world however the emergence of MDR strains of Shigella spp. has made the treatment for shigellosis more difficult. The emergence of MDR Shigella has been reported from all over the world including USA, Iran, China, Indonesia, Vietnam, Bangladesh and India. Outbreak investigations of Shigella species in India (Chandigarh, Siliguri, Aizawl and Diamond Harbour Kolkata) showed high level resistance to fluoroquinolones (Sarkar et al., 2003). At our centre also we observed ciprofloxacin resistance among $S$. sonnei isolates.

In a study from Southern China Cao et al., (2014) had reported S. sonnei resistance to ampicillin, ceftriaxone and cefotaxime whereas our isolates were sensitive to all these drugs.

The present outbreak occurred in the month of June which is quite hot and dry season in Rajasthan Shigella infections can occur round the year, but peak prevalence in summer months has been reported (Thapa et al., 1995). In most communities the incidence is highest in hot and dry weather, possibly because the scarcity of water in such conditions limits hand-washing and other hygiene measures that reduce person-toperson transfer of the bacteria.

This outbreak indicates that in India food and waterborne routes for transmission of Shigellosis may not be so uncommon and this reinforces the need to provide adequate sanitation.

Better awareness about general measures such as washing, peeling and cooking of all fruits and vegetables, avoidance of food preparation by personnel who change diapers in day care centres, proper handling and refrigeration of food, encouraging prolonged breastfeeding in 
infants, and appropriate case reporting to health authorities may be helpful to prevent such outbreaks. Community health education must emphasize upon good personal hygiene, adequate disposal of faeces, as well as the imminent threat of MDR pathogens.

In conclusion, Shigellosis is one of the major causes of diarrhoea in India. S. sonnei and Non-agglutinable Shigella are steadily surfacing; judicious use of antibiotics for Shigella is amongst the most essential measure to combat Shigellosis. The case reporting of Shigellosis is desirable as it will substantially reduce the morbidity associated with diarrhoea in country.

\section{Acknowledgement}

We thank to all health care workers and laboratory personnel who helped in outbreak investigations, specimen collection, and strain isolation. We gratefully acknowledge NCDC New Delhi for confirmation of Shigella sonnei isolates.

\section{References}

Adams, M.R. and M.O. Moss. 2003. Significance of food borne diseases. Food Microbiol., 2(163): 160-164.

Bardhan, P., Farque, A., Naheed, A., Sack, D.A. 2010. Decrease in shigellosis related deaths without Shigella spp. specific intervention, Asia. Emerg. Infect. Dis., 16: 1718 - 1723.

Cao, J., Zhang, X., Zhou, T., lu, Y., Hou, J., Guo, M., Win, Q. 2014. IJMM., 32(1): 95-96.

Clinical and Laboratory Standards Institute. 2005. Performance standards for antimicrobial susceptibility testing; fifteenth informational supplement. Wayne, PA.: Clinical and Laboratory Standards Institute, Approved standard M100-S15
Dutta, D., Bhattacharya, M.K., Dutta, S., Datta, A., Sarkar, D., Bhandari, B. 2003. Emergence of multidrug-resistant Shigella dysenteriae type 1 causing sporadic outbreak in and around Kolkata, India. J. Health Popul. Nutr., 21: 79-80.

Holt, K.E., Baker, S., Weill, F.X., Holmes, E., Kitchen, A., Yu, J. 2012. Shigella sonnei genome sequencing and phylogenetic analysis indicate recent global dissemination from Europe. Nat Genet., 44: 1056-9.

Kotloff, K.L., Nataro, J.P., Blackwelder, W.C., Nasrin, D., Farag, T.H., et al. 2013. Burden and aetiology of diarrhoeal disease in infants and young children in developing countries (the Global Entric Multicenter Study, GEMS): a prospective, case - control study. Lancet, 382: $209-222$.

Manual of clinical microbiology. 6th ed. Washington, DC, American Society for Microbiol., p. 1: 482.

Nandy, S., Dutta, S., Ghosh, S., Ganai, A., Rajahamsan, J., Theodore, R.B., et al. 2011. Food borne-associated Shigella sonnei, India, 2009 and 2010. Emerg. Infect. Dis., 17: 2072-4.

Newell, D.G., M. Koopmans, L. Verhoef et al. 2010. "Food-borne diseases-the challenges of 20 years ago still persist while new ones continue to emerge," Int. J. Food Microbiol., vol. 139, supplement 1, pp. S3-S15.

Prehel, M., Gonzalez Fraga, S., Terrango, R., Mulki, J., Gentile, A., Kremer, C., et al. 2007. Short report: analysis of clonal relationship among Shigella sonnei isolates circulating in Argentina. Epidemiol. Infect., 135: 681 - 7 .

Sarkar, K., Ghosh, S., Niyogi, S.K., Bhattacharya, S.K. 2003. Shigella dysenteriae type 1 with reduced susceptibility to fluoroquinolones. Lancet., 361: 785. 
Scallan, E., Hoekstra, R.M., Angulo, F.T., Tauxe, R.V., Widdowson, M.A., Roy, S.L. et al. 2011. Food borne illness acquired in the United States - major pathogens. Emerg. Infect. Dis., 17: 715.

Steffen, R. 2005. Epidemiology of traveler's diarrhea. Clin. Infect. Dis., 41: S536-40.

Sudershan, R.V., R.N. Kumar, and K. Polasa. 2012. Food borne diseases in India - a review. British Food J., 114(5): 661680.

Taneja, N. and Mewara. 2016. Shigellosis: Epidemiology in India, Indian J. Med. Res., 143(5): 565-576.

Thapa, B.R., Ventkateswarlu, K., Malik, A.K., Panigrahi, D. 1995. Shigellosis in children from north India: a clinicopathological study. J. Trop. Pediatr., 41: 303-7.

Thapar, N., Sanderson, I.R. 2004. Diarrhoea in children: an interface between developing and developed countries. Lancet, 363: 641 - 653 .

Vinh, H., Nhu, N.T.K., Ngr, T.V.T., Duy, P.T., Campbell, J.I., Hoang, N.V.M., et al. 2009. A changing picture of Shigellosis in Southeren Vietnam: Shifting species dominance, antimicrobial susceptibility and clinical presentation. BMC Infect. Dis., 9: 204.

Von Seidlein, L., Kim, D.R.,. Ali, M.,. Lec, H,. Wang, X., Thiem, V.D., et al. 2006. A multicenter study of Shigella diarrhoea in six Asian countries: disease burden, clinical manifestations and microbiology. PLoS Med., 3: e 353.

\section{How to cite this article:}

Reena Goyal, Taruna Swami, Deep Shikhar Acharya and Divya Sharma. 2017. Food Borne Outbreak of Gastroenteritis Due to Shigella sonnei in North - West Region of Rajasthan, India. Int.J.Curr.Microbiol.App.Sci. 6(3): 331-335. doi: https://doi.org/10.20546/ijcmas.2017.603.037 